\title{
Pulmonary embolism presenting with ST segment elevation in inferior leads 论
}

\author{
Muzaffer Kahyaoğlu* * Elnur Alizade, Abdurrahman Naser, Akin İzgi \\ Kartal Kosuyolu Heart Education and Research Hospital, Istanbul, Turkey
}

\section{A R T I C L E I N F O}

\section{Article history:}

Received 30 March 2016

Received in revised form 19 January 2017

Accepted 20 February 2017

Available online 24 February 2017

\section{Keywords:}

Pulmonary embolism

Electrocardiogram

Myocardial infarction

\begin{abstract}
A B S T R A C T
Acute pulmonary embolism is a form of venous thromboembolism that is widespread and sometimes mortal. The clinical presentation of pulmonary embolism is variable and often nonspecific making the diagnosis challenging. In this report, we present a case of pulmonary embolism characterized by ST segment elevation in inferior leads without reciprocal changes in the electrocardiogram.

(C) 2016 The Society of Cardiovascular Academy. Production and hosting by Elsevier B.V. This is an open access article
\end{abstract} under the CC BY-NC-ND license (http://creativecommons.org/licenses/by-nc-nd/4.0/).

\section{Introduction}

Acute pulmonary embolism (PE) is a form of venous thromboembolism (VTE) that is widespread and sometimes mortal. ${ }^{1}$ The clinical presentation of PE is variable and often nonspecific making the diagnosis challenging. ${ }^{2}$ Patients can be diagnosed and therapy administered quickly to reduce the associated morbidity and mortality. ${ }^{3}$ Electrocardiographic (ECG) changes are very unspecific and range from most common sinus tachycardia, rightward shift in QRS axis, complete or incomplete right bundle branch block, precordial T wave inversion, S1Q3T3 pattern and more uncommon ST segment elevation. ${ }^{4}$ In this report, we present case of pulmonary embolism characterized by ST segment elevation in inferior leads without reciprocal changes in the electrocardiogram (ECG).

\section{Case report}

76 year-old female patient was admitted to our emergency department because of chest pain and acute onset breathlessness. Her past medical history included hypertension and her coronary angiography showed normal coronary artery two years priorly. She was getting immobile because of left arm fracture for six months. On physical examination, her blood pressure was 102/65 mm Hg, heart rate was $102 \mathrm{bpm}$ and oxygen saturation was $88 \%$. Electrocardiography (ECG) showed ST segment elevation in inferior leads without no reciprocal changes (Fig. 1). Transthoracic echocardiography revealed normal left ventricular systolic function without segmental contraction defects and slightly right ventricular enlargement. Systolic pulmonary pressure was

\footnotetext{
is Peer review under responsibility of The Society of Cardiovascular Academy.

* Corresponding author at: Kartal Kosuyolu Heart Education and Research Hospital, Cevizli mah. Denizer Cad. No: 2 Kartal, Istanbul, Turkey.

E-mail address: mkahyaoglu09@hotmail.com (M. Kahyaoğlu).
}

$45 \mathrm{~mm} \mathrm{Hg}$ and tricuspid annular plane systolic excursion (TAPSE) and tricuspid annular velocity were $16 \mathrm{~mm}$ and $10 \mathrm{~cm} / \mathrm{s}$, respectively. Laboratory test results were unremarkable but troponin-I level increased. Re-tests $3 \mathrm{~h}$ later, there was no changes according to first troponin level. On the basis of physical examination, past medical history, ST segment elevation without no reciprocal changes, pulmonary embolism was suspected. Then we performed contrast-enhanced chest computed tomography. Chest computed tomography scan showed pulmonary embolism (Fig. 2). At the time of diagnosis of pulmonary embolism she was hemodynamically stable, therefore she received continuous infusion of unfractionated heparin. After 5 days heparin infusion, ECG changes was getting normal and ST segment elevation in inferior leads was resolved (Fig. 3). In a few days heparin, infusion was substituted for warfarin and enoxaparin. International normalized ratio (INR) level became therapeutic range and she discharged successfully.

\section{Discussion}

The symptoms and clinical features of pulmonary embolism are variable. ${ }^{2}$ As stated previously, pulmonary embolism present several electrocardiographic (ECG) changes but ST segment elevation is rare condition. We demonstrated this rare condition in pulmonary embolism. This case highlights the fact that pulmonary embolism still remains one of the biggest masqueraders in acute coronary syndrome. Physicians should be careful in patients presenting with ST segment elevation and pulmonary embolism should be kept in mind differential diagnosis of acute coronary syndrome.

\section{Conflict of interest}

None. 


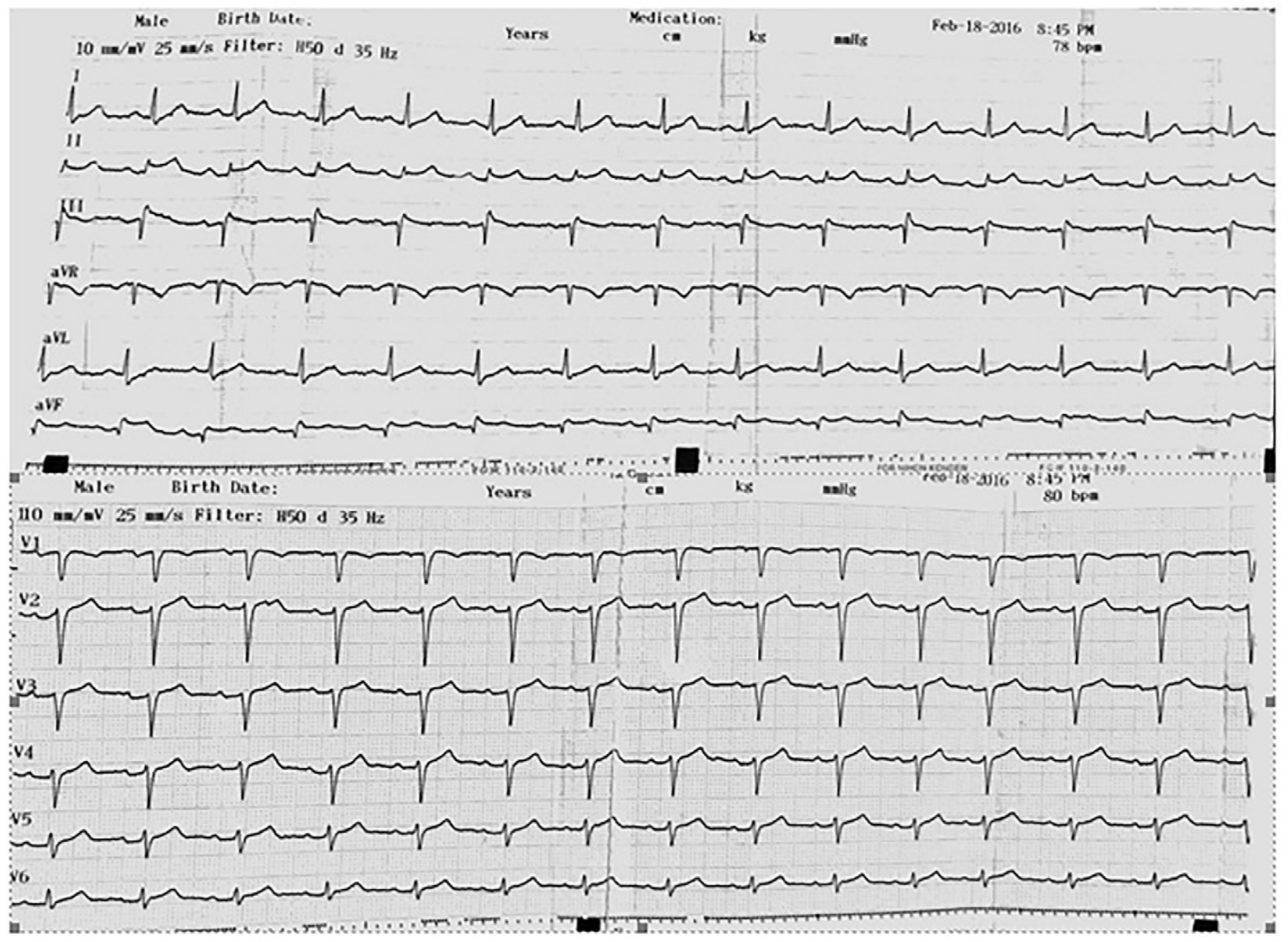

Fig. 1. The ECG shows ST Segment elevation in inferior leads without reciprocal changes.

\section{References}

1. Heit JA. The epidemiology of venous thromboembolism in the community. Arterioscler Thromb Vasc Biol 2008;28(3):370-372.

2. Stein PD, Terrin ML, Hales CA, et al. Clinical, laboratory, roentgenographic, and electrocardiographic findings in patients with acute pulmonary embolism and no pre-existing cardiac or pulmonary disease. Chest 1991;100:598-603.
3. Goldhaber SZ, Visani L, De Rosa M. Acute pulmonary embolism: clinical outcomes in the International Cooperative Pulmonary Embolism Registry (ICOPER). Lancet 1999;353:1386-1389.

4. Pollack ML. ECG manifestations of selected extracardiac diseases. Emerg Med Clin North Am 2006;24(1):133-143 [vii]. 

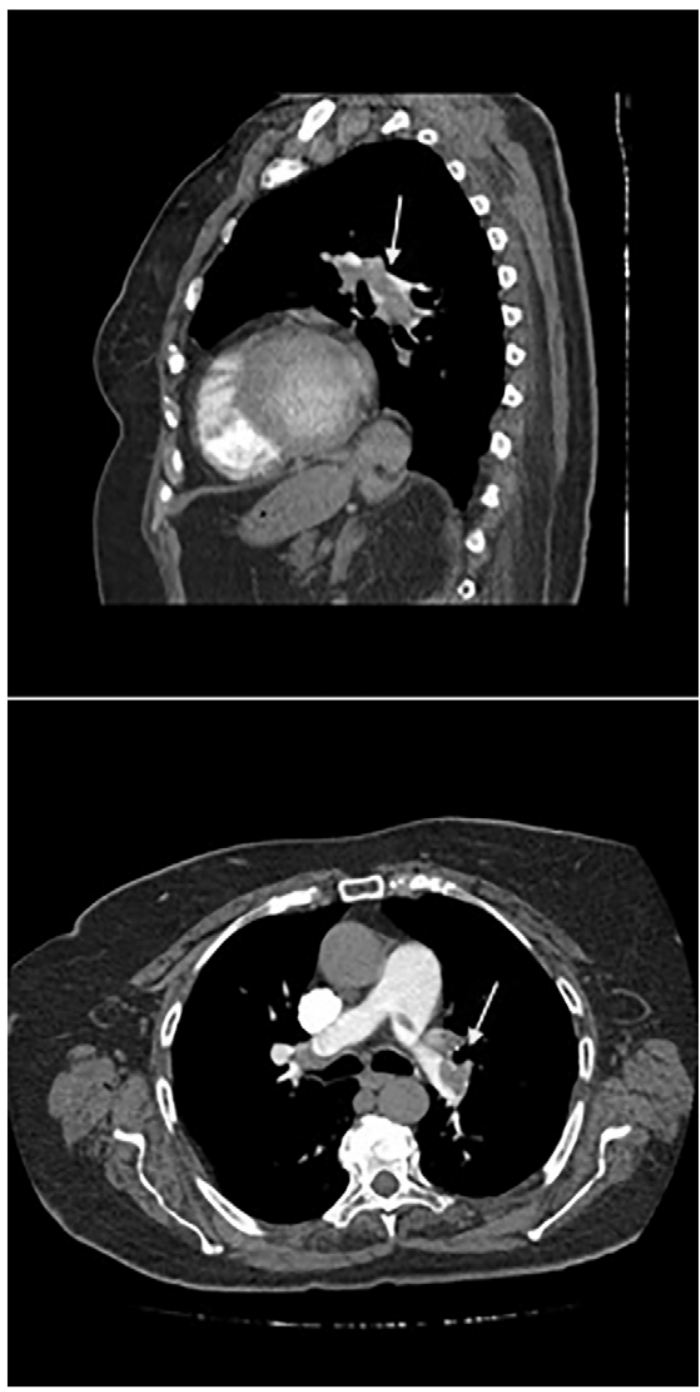

Fig. 2. Computed Tomography shows pulmonary embolism. 
44

M. Kahyaoğlu et al. / International Journal of the Cardiovascular Academy 3 (2017) 41-44

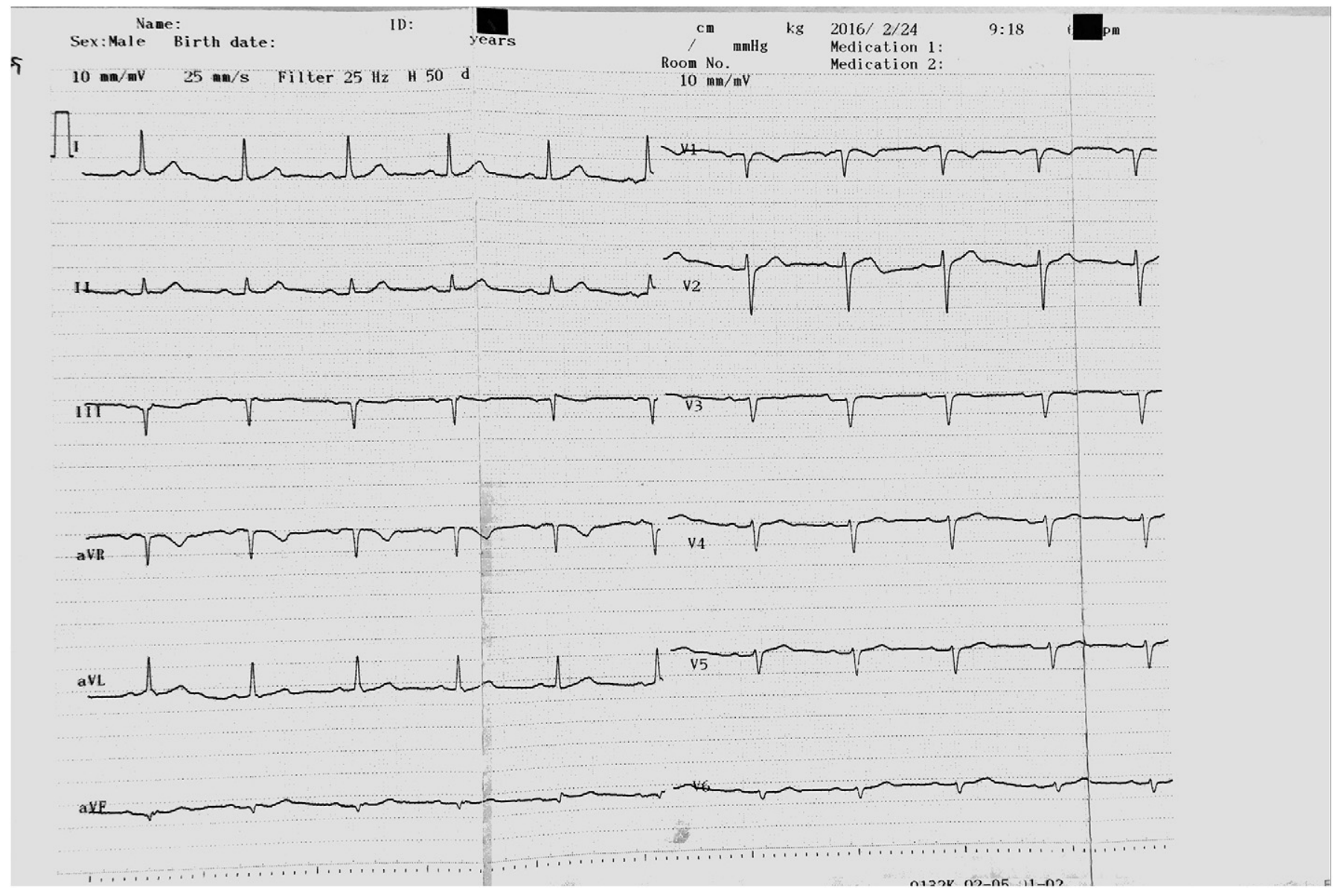

Fig. 3. The ECG shows resolution of ST segment elevation after anticoagulation treatment. 